LUXIÉRNAGA

Miriam Romero Jiménez 


\section{John Locke: Apuntes del Ensayo sobre el entendimiento humano}

\section{Introducción}

Este es un trabajo de investigación documental basado en el pensamiento de John Locke, para rescatar, las aportaciones filosóficas que éste autor planteó desde el s. XVII, y sirve como base para retomar una directriz fiable para reflexionar sobre la actividad del entendimiento humano, es decir, analizar su naturaleza, sus alcances, y principales procesos.

Con el objetivo de indagar en las cuestiones fundamentales del reflexionar humano, nos preguntamos ¿Cómo es que conocemos? ¿por qué creemos?, en una perspectiva similar a la de John Locke, bajo un enfoque filosófico estrictamente empirista, descartando toda noción sobre la existencia de ideas innatas, es decir, asumiendo, que el inicio del conocimiento humano se da a partir del nacimiento; pues conjeturar de otra manera, implicaría caer en juicios supersticiosos.

Para John Locke enfrentar el problema sobre los límites del entendimiento humano, necesariamente, le remite a lo empíricamente observable a partir del nacimiento del ser humano. Así se irán desarrollando los conceptos fundamentales de este tema acerca de las impresiones, las ideas y las palabras en el desarrollo del presente apartado.

Para entender a John Locke hay que retomar las ideas de René Descartes y para seguir el rastro de las ideas de Descartes, no hay que perder de vista que Al-Ghazali, se hizo casi idénticas preguntas, dando casi perecidas respuestas; y aunque Descartes no da crédito a éste filósofo de origen musulmán, es nuestro deber no volver a omitir este hecho.

\section{Al-Ghazali y el antecedente de la tabula rasa}

Cada que enfrentamos un nuevo acto de conocimiento, nos encontramos con la disyuntiva de creer, o no creer, en la nueva información que se devela ante nuestros 
sentidos. En todo acto vivencial codificamos información, ya sea en forma de palabras; o en forma de impresiones sensitivas, es decir, la información de imágenes visuales, memorias auditivas, sensaciones táctiles, olores, sabores, que perciben nuestros sentidos y quedan grabados en nuestra memoria, posiblemente, de forma permanente.

Al-Ghazali, en su texto, El salvador del error, se enfrenta al problema de la demarcación del conocimiento y se pregunta "cómo desatar el nudo de la imaginación ciega y para que se resquebrajen las creencias heredadas." En este sentido, el autor examina la necesidad de delimitar la imaginación ciega, que se deriva de actos inconmensurables de lo que hoy atribuimos al concepto de mente, sus conexiones simbólicas y analógicas, sea a partir de la experiencia y sus juicios a posteriori, sumado a la extensión ilimitada de los juicios sintéticos a priorí, que representan gran parte de nuestra imaginación y entendimiento.

Para Al-Ghazali, "todo niño nace en un estado de naturaleza pura," ${ }^{2}$ una reflexión similar a la concepción de la tabula rasa propuesta por John Locke. Y, sin sacar un juicio fuera de contexto, continúa Al-Ghazali asumiendo que: "son sus padres los que hacen de él un judío, un cristiano o un zoroastra." ${ }^{3}$ En este trabajo, no se enjuicia la validez de las creencias religiosas del filósofo Al-Ghazali, sino el sentido de sus propuestas; primeramente, ¿a qué se refiere Al-Ghazali acerca de las «creencias heredadas»? ¿cuál es el estado de naturaleza pura del niño cuando nace? Es evidente que Al-Ghazali se refiere a las «creencias religiosas heredadas», que implican cosmovisiones metafísicas sobre el origen del universo; leyes primordiales, como en el caso de las leyes mosáicas, que conforman los marcos éticos, morales y jurídicos, que regulan el actuar de éstas civilizaciones, inclusive el desarrollo del avance científico, político, teológico y filosófico. El estado de «naturaleza pura» del recién nacido, es no estar predestinado a ser de cierta religión cuando se nace, pues no se posee conocimiento innato, son los padres, quienes a través de las enseñanzas doctrinales y culturales van a heredar al niño

\footnotetext{
${ }^{1}$ Algazel, El salvador del error confesiones, Trotta, Madrid, 2013, p. 31.

${ }^{2}$ Ídem. p. 31.

${ }^{3}$ Ibídem. p. 31.
} 
cierta cosmovisión del mundo, lo anterior regulará también su conducta e interacción social; éstas enseñanzas familiares afectarán al neonato de manera multifactorial, en su psiquismo, en su interpretación del mundo, en el lenguaje, la expresión artística, en la alienación a ciertos grupos de referencia, inclusive en sus gustos, forma de vestir y de comportarse, elección de pareja, etc. Todas esas creencias derivadas de cierta cosmovisión religiosa y cultural se transferirán de generación en generación a través de las costumbres, y son interiorizadas por nuevas formaciones familiares que preservan la cultura y las creencias.

Lo que asumimos como conocimiento, es una infinidad de consensos sociales, como los «acuerdos de juicios unánimes», ${ }^{4}$ temporales; basados en juicios contingentes, que lejos de representar verdades indubitables, son sólo conjuntos de ideaciones humanas, no importando su carácter apodíctico como verdades concluyentes; además, son de interpretaciones subjetivas, que penden de la elucidación historicista de cada sujeto.

Al-Ghazali, se cuestiona sobre el origen del conocimiento, buscando en:

La verdadera naturaleza originaria, la verdad de las creencias que provienen de seguir ciegamente a los padres y maestros y el discernimiento entre estas creencias recibidas cuyos principios son dictados desde fuera del propio individuo y en los que hay divergencias respecto a la distinción entre lo verdadero y lo falso. ${ }^{5}$

Es sólo a través de las «creencias heredadas», es decir, del acto de continuar con las creencias enseñadas por los padres, maestros y diversos actores de la sociedad, que el progreso histórico y cultural se preserva y sirve como base para avanzar en el perfeccionamiento histórico del conocimiento humano. creencias que se heredan de generación en generación, es decir, como supone Kant en su ensayo: Idea para una historia universal en clave cosmopolita, "En el hombre (como única criatura racional sobre la tierra) aquellas disposiciones naturales que tienden al uso de su razón, sólo deben desarrollarse por completo en la especie, mas no en el individuo" ${ }^{6}$, de tal forma,

\footnotetext{
${ }^{4}$ Paráfrasis de la definición de consenso, véase: Cassin, Bárbara (2018), p. 305.

${ }^{5}$ Óp. Cit, Algazel, (2013), p. 31.

${ }^{6}$ Kant, ¿Qué es la Ilustración?, en Grandes Pensadores, Gredos, España, 2014, p. 331.
} 
que se asume la naturaleza finita del sujeto y sus alcances vivenciales, existenciales, para conjuntar en suma, con cada uno de ellos el conocimiento de la especie humana, es decir, del progreso histórico y cultural. Para Kant es una serie "interminable de generaciones que trasmitan la una a la otra su ilustración"7 lo que conjunta el progreso de la historia humana.

Para Al-Ghazali es fundamental buscar el conocimiento de las verdaderas naturalezas de las cosas, narra en sus Confesiones, que "el conocimiento cierto es aquel en el que se descubre lo conocido de un modo que no deja lugar a dudas". Primeramente reflexiona en conseguir un conocimiento a partir de las cosas claras y no problemáticas, esas cosas claras son extraídas de "los datos sensibles y los primeros principios," no sin dudar de que esos datos sensibles puedan estar a salvo del error; una vez puestos en duda los datos sensibles, Al-Ghazali observa que: "Aquellas largas vacilaciones me determinaron a no dar crédito tampoco a los datos sensibles" I0; y propone el ejemplo de una sombra que se observa a través del sentido de la vista siendo este sentido el más confiable, pero es engañado cuando contempla la sombra que en apariencia permanece estática, quieta o inmóvil; sin embargo, al cabo del tiempo la sombra cambia de lugar, por lo tanto, existe movimiento imperceptible para los sentidos humanos de manera inmediata, entonces, nos llega el "árbitro de la razón y nos declara falsos"II. Al igual que Descartes hace en las Meditaciones metafísicas; Al-Ghazali se despoja de todas sus creencias procedentes de los juicios humanos y de los datos sensibles extraídos a través de los sentidos humanos, y cae en un escepticismo profundo, que resuelve a través de la fe en las enseñanzas del Corán. Un relato muy parecido al que siglos después relata Descartes, pero éste, no resuelve el problema del escepticismo refugiándose en las creencias doctrinales de una religión, sino, en su premisa, "pienso, luego, existo».

\footnotetext{
${ }^{7}$ Ídem. p. 331.

8 Óp. Cit. Algazel, (2013), p. 31.

${ }^{9}$ Ídem. p. 33.

${ }^{10}$ Ibídem. p.33.

${ }^{11}$ Ídem. p. 34.
} 


\section{John Locke y los límites del entendimiento humano}

John Locke, en su Ensayo sobre el entendimiento humano, inicia resaltando la importancia de reflexionar acerca de la naturaleza del propio entendimiento y sus alcances, ejemplificando, a través de la metáfora del ojo que percibe las demás cosas, pero no se observa a sí mismo; de tal forma que Locke, revierte el objeto de estudio sobre el propio entendimiento que reflexiona sobre las cosas del mundo. Locke coloca al hombre por encima de todos los «seres sensibles», gracias a la facultad propia del intelecto humano.

Indagar sobre "los orígenes, la certidumbre y los alcances del entendimiento humano, junto con los fundamentos y grados de creencias, opiniones y asentimientos" ${ }^{2}$ es el objetivo filosófico de Locke, claramente bajo una visión empirista, a partir de la experiencia adquirida después del nacimiento del sujeto. Así lo menciona en su texto, no es de su interés profundizar en "consideraciones físicas de la mente" ${ }^{13}$, que en nuestro contexto se refiere a los procesos cerebrales, conexiones sinápticas químicas o electroquímicas.

Locke, en el escolio 2 de la introducción de su obra, delimita su propósito por investigar sólo "los orígenes, la certidumbre y el alcance del entendimiento humano, junto con los fundamentos y grados de creencia, opiniones y asentimientos" I4 delimitando claramente:

No me meteré aquí en consideraciones físicas de la mente, ni me ocuparé en examinar en qué puede consistir su esencia, o por qué mociones de nuestros espíritus o alteraciones de nuestros cuerpos llegamos a tener sensaciones en nuestros órganos, o ideas en nuestro entendimiento, si en formación esas ideas, algunas o todas, dependen o no de la materia. ${ }^{15}$

Es importante hacer notar cómo es que Locke en su ejercicio de especulación filosófica sobre los alcances y la naturaleza del entendimiento humano, realizó un paréntesis

\footnotetext{
${ }^{12}$ Locke, John, Ensayo sobre el entendimiento humano, Fondo de Cultura Económica, 2a . Ed., México, 1999, p. 17.

${ }^{13}$ Ídem.

${ }^{14}$ Ibídem p. 17.

${ }^{15}$ Ibídem. 17
} 
(epojé), al dejar de lado este tipo de teorías por no obedecer al objetivo de estudio que se planteaba. La intención de Locke fue sólo, creemos, tomar en cuenta las facultades del discernimiento humano proyectado sobre los objetos de que se ocupa. Locke sólo utilizó un enfoque histórico y psicológico que validaba la forma en la cual el entendimiento procesa:

Esas nociones que tenemos de las cosas, y si puedo establecer algunas reglas de la certidumbre de nuestro conocimiento y mostrar los fundamentos de esas persuasiones que se encuentran entre los hombres, tan varias, distintas y del todo contradictorias, pero afirmadas, sin embargo, en algún lugar, con tanta seguridad y confianza, que quien considere las opiniones de los hombres, observe sus contradicciones y a la vez considere el cariño y devoción con que son tenidas, y la resolución y vehemencia con que se les defiende, quizá llegue a sospechar que o bien no hay eso que se llama la verdad, o que el hombre no posee los medios suficientes para alcanzar un conocimiento cierto de ella. ${ }^{16}$

Locke rechaza rotundamente la existencia de las ideas innatas; ya que anteriormente a él, en el desarrollo histórico de la especulación filosófica, se habían supuesto "ciertos principios innatos, ciertas nociones primarias $[\ldots]$ como si estuvieran estampados en la mente humana, y que el alma los recibe en su origen, trayéndolos al mundo con ella"17 Locke, exalta "la falsedad de esta suposición"18 de manera directa y clara, e intenta demostrar en el desarrollo de su obra, cómo es que el ser humano a través de las facultades naturales del entendimiento, puede adquirir todo el conocimiento que posee.

\section{La tabula rasa y el origen empírico de las ideas según Locke.}

Locke inicia el libro segundo del Ensayo sobre el entendimiento humano, argumentando sobre el origen de las ideas en general. En el primer capítulo de este, en el primer escolio, sostenemos que la idea misma "es el objeto del acto de pensar," 19 pues el hombre es consciente de que piensa y posee infinidad de ideas en el alma o consciencia, expresadas a través de las palabras, por ejemplo las ideas de: "blancura, dureza, dulzura, pensar,

\footnotetext{
${ }^{16}$ Ibídem, p. 17-18.

${ }^{17}$ Locke, John, Ensayo sobre el entendimiento humano, en Grandes Pensadores, Gredos, Madrid, 2015, p. 11.

18 Ídem.

${ }^{19}$ Óp. Cit, John Locke, Ensayo sobre el entendimiento humano, p. 83.
} 
moción, hombre, elefante, ejercito, ebriedad y otras" ${ }^{20}$. Para Locke es importante saber cómo es que se obtienen éstas ideas, y vislumbra el origen de las primeras impresiones en el momento de nacer; admite que "es doctrina recibida que los hombres tienen ideas natas y ciertos caracteres originarios impresos en la mente desde el primer momento de su ser" ${ }^{21}$, asumiendo que esa impresión de caracteres que originan las ideas provienen de la observación y la experiencia del sujeto. Iniciando así, la dirección de especulación empirista sobre procesos de conocimiento en el hombre, que más tarde desarrollaran Hume y Berkeley.

Según Locke, todas las ideas provienen de la sensación o de la reflexión, argumentando a partir de la concepción de la tabula rasa:

Supongamos, entonces, que la mente sea, como se dice, un papel en blanco, limpio de toda inscripción, sin ninguna idea. ¿Cómo llega a tenerlas? ¿De dónde se hace la mente de ese prodigioso cúmulo que la activa e ilimitada imaginación del hombre ha pintado en ella, en una variedad casi infinita? ¿De dónde saca todo ese material de la razón y del conocimiento? A esto contesto con una sola palabra, de la experiencia. ${ }^{22}$

Así para Locke, "Todas las ideas vienen de la sensación o de la reflexión," 23 asumiendo como fundamento de todo saber a la experiencia humana, que deriva en sensación y posteriormente en productos de la razón.

Locke emplea la palabra undrstanding, como fundamento de su propuesta filosófica, undertanding: se traduce al español como: 'entendimiento', y es parte fundamental del título del presente ensayo; sobre esto esclarecemos los límites de las relaciones existentes entre mente y entendimiento, con ello, Locke inaugura una nueva tradición sobre el estudio del entendimiento que retomará Hume.

Locke divide el lado pasivo y el lado activo del funcionamiento mental en adquisiciones de ideas (percepción en sentido amplio) que le competen al entendimiento, y acciones de la voluntad (will), el undersending ya sólo es una parte del mind. ${ }^{24}$

\footnotetext{
${ }^{20}$ Ibídem. p. 83.

${ }^{21}$ Ibídem. p. 83.

22 Ibídem. p. 83.

${ }^{23}$ Ibídem, p. 83.

${ }^{24}$ Óp. Cit. Cassin, Bárbara, Vocabulario de las filosofías occidentales: Diccionario de los intraducibles. tomo 1 (2018), p. 79.
} 
El pensamiento de John Locke, sirve como punto de partida sobre el estudio del entendimiento, que posteriormente retomarán Hume, Berkeley, Kant y futuros pensadores, psiquiatras y filósofos. Locke trató de entender cuáles son los orígenes del entendimiento humano, es decir, los procesos mentales; haciendo un ejercicio regresivo de manera temporal, hasta observar las primeras impresiones sensitivas adquiridas a partir del nacimiento, advirtiendo que gran parte de la información impresa en nuestra mente a través de los sentidos, es olvidada, y las personas no tienen registro de cómo se elaboran las primeras impresiones humanas, que representan el conocimiento del propio individuo. Para Locke, lo que se observa en los niños recién nacidos, es, que no nacen abarrotados de ideas, sino que gradualmente, a través de la experiencia, es que éste provee de ideas al entendimiento; antes de que la memoria conozca el registro del tiempo y del orden, que el neonato no ha aprendido a mesurar; son los familiares quienes imprimen en el recién nacido ciertos conocimientos primordiales; el recién nacido, evidentemente, no ha desarrollado las habilidades somáticas para iniciarse en el lenguaje, pero si en cierto tipo de ideas sensoriales, todos los seres humanos, según Locke, están rodeados de otros cuerpos que continuamente le afectan, de tal forma que: "gran variedad de ideas se imprimen en la mente de los niños." 25 También manifiesta que: "son pocos los hombres que no pueden recordar el tiempo cuando por primera vez las conocieron," ${ }^{26}$ refiriéndose a las impresiones de las cosas en nuestra mente, así, Locke vislumbra cierta actividad de la mente que es olvidada, aunque se haya impreso en la memoria, nos lleva a cuestionar ¿Por qué se olvidan las cosas?, es decir, las impresiones. Siglos más tarde Freud asumirá que gran parte de este fenómeno mental se refiere a procesos económicos del sistema psíquico, dando paso a la teoría sobre una actividad inconsciente. Ya sea por aquello que se olvida o que se reprime.

Locke observa que:

${ }^{25}$ Óp. Cit, John Locke, Ensayo sobre el entendimiento humano, p. 85.

${ }^{26}$ Ibídem. p, 85. 
La luz y los colores están en todas partes en constante disposición de causar impresiones, con sólo que el ojo esté abierto; el sonido y algunas cualidades tangibles no dejan de solicitar a los sentidos que les son propios, $y$ de ese modo se abren paso hasta la mente. ${ }^{27}$

Lo anterior sirve para justificar, cómo es que la discursiva filosófica cruza en el objeto de estudio del psicoanálisis, es decir, el entendimiento humano derivado en actividad psíquica, teoría que se desarrollará más de 200 años después y que a través del análisis discursivo en observaciones de intervención clínica, se pudo conjeturar acerca de las actividades de la consciencia, que es una manera narrativa de acceder al producto del entendimiento humano, que como ya mencionamos, su objeto fundamental es la generación de ideas, expresadas en palabras.

\section{La teorización acerca de la actividad onírica bajo la apreciación de Locke.}

Para Locke "el alma no piensa siempre," 28 admite que él es un tipo de persona que no siempre tiene consciencia de que piensa, y aunque pensar, es supuestamente la acción propia del alma, no siempre se está pensando, por ejemplo, en un estado onírico, "yo no digo que no hay alma en un hombre porque no la perciba en su sueño, pero sí digo que no puede pensar a cualquier hora que sea, durmiendo o en estado de vigilia, sin que sea consciente de ello." ${ }^{29}$ Para Locke es fácil suponer que "hay algo en nosotros que tiene el poder de pensar," 30 pero no se puede tener certeza de que permanentemente se piensa, y "decir que el pensar actual es esencial al alma e inseparable de ella es incurrir en una petición de principio." 31

Para Locke es "es muy difícil concebir que algo piensa sin ser consciente de ello." 32 Sólo teniendo un testigo visual que dé fe de que se piensa mientras se duerme; pone el ejemplo de un reloj, que no sabemos si la mente trabajó durante toda la noche

\footnotetext{
${ }^{27}$ Ibídem. p. 85.

28 Ídem. p. 87.

${ }^{29}$ Montes de Oca, Francisco, La filosofía en sus fuentes, Porrúa, México, 1971, p. 270.

${ }^{30}$ Óp. Cit, John Locke, Ensayo sobre el entendimiento humano, p. 87

${ }^{31}$ Ibídem. p. 87.

${ }^{32}$ Óp. Cit. Montes de Oca, Francisco, La filosofía en sus fuentes, (1971), p. 271.
} 
mientras dormíamos y el hacer suposiciones o hipótesis sobre ésta premisa no se fundamenta en una experiencia sensible, de lo contrario es una simple presunción del hecho que apoya una supuesta hipótesis. En analogía al ser humano, suponer que "durante toda la noche anterior estuve pensando, porque otra persona supone que siempre estoy pensando, aunque yo mismo no pueda percibir que siempre pienso." ${ }^{33}$ En esta frase de Locke se pueden venir abajo nuestras expectativas sobre la neurociencia, pues un sujeto en un estado onírico, al estar conectado a una máquina que detecte la actividad cerebral, y un neurocientífico que la vigile, y suponga que el sujeto, objeto de estudio, está pensando, es sólo una conjetura, pues es sólo el sujeto que al despertar podría dar testimonio de ello, y si no recuerda nada, entonces no tenemos certeza de que piense durante el estado onírico. Según Locke "el alma no es siempre consciente de que piensa," ${ }^{34}$ y lo ejemplifica asumiendo que:

Sócrates dormido y Sócrates despierto no son la misma persona; sino que el alma de Sócrates, cuando duerme, y Sócrates el hombre, compuesto de cuerpo y alma cuando está despierto, son dos personas; puesto que Sócrates despierto no tiene conocimiento de, ni le importa, esa felicidad o miseria que su alma experimenta sola y por sí misma mientras él duerme, sin percibir nada de ello, y le es tan ajeno como la felicidad o miseria de un hombre en las Indias, cuya existencia enteramente desconoce. ${ }^{35}$

Se observa claramente que Locke no conoció lo que hoy se denomina 'trastornos del sueño', que, en el caso de las pesadillas recurrentes, la felicidad, la angustia o la miseria que se experimenta, también a través del sueño, mantiene a los sujetos en la vigilia angustiados y con miedo a tener que volver a dormir. Para Locke, "el hombre dormido y el hombre despierto son dos personas distintas, el hombre que duerme no tiene conciencia de ello ni tampoco "conciencia ni percepción alguna," 36 lo anterior es entendible, según la experiencia de Locke, creer en la narración de otra persona que diga lo contrario, representa un acto de fe.

\footnotetext{
${ }_{33}$ Óp. Cit, John Locke, Ensayo sobre el entendimiento humano, p. 88.

${ }^{34}$ Ibídem. p. 88.

35 Ídem. p. 89.

${ }^{36}$ Ídem. P. 90.
} 


\section{Conclusión}

Gracias a ésta investigación podemos concluir, que es importante indagar analíticamente en las distintas formas de las actividades del entendimiento humano, examinar cómo es que se originan las representaciones psíquicas, las abstracciones mentales, y cómo esto conlleva a nuestra interpretación del mundo, que en la suma de nuestros pensamientos subjetivos podemos llegar a acuerdos consensuados de entender la realidad del mundo.

Es importante analizar las formaciones psíquicas desde el origen de cada vida humana, es decir, desde el nacimiento, para esclarecer la naturaleza del propio conocimiento, sin omitir, la naturaleza contingente y finita; no necesaria de cada ser humano, que no puede acceder a la totalidad del conocimiento y es gracias a la herencia cultural que avanzamos; pues hay muchas ideologías supersticiosas dentro de diversos campos de conocimiento, que desvían la atención, inclusive en la filosofía, por ejemplo, en la concepción de un 'Espíritu Absoluto' de tintes hegelianos. El ser humano es susceptible de manipulación por grupos sectarios, políticos y nuevas ideologías radicales.

Es importante rescatar el pensamiento de John Locke para saber cómo es que, desde el inicio de la vida, la actividad del entendimiento quedará en la memoria de cada sujeto. El inicio en la idea de una tabula rasa, que Al-Ghazali también llamó estado de naturaleza pura, y son las creencias de los padres los que determinan el pensamiento del niño. 